\section{A Potential Gap in Access to Anesthetic Care for Patients with Special Considerations}

\author{
Felicia Hasta*, Rahul Koka and Philip Carullo
}

Department of Anesthesiology and Critical Care Medicine, Division of Pediatric Anesthesiology, Johns Hopkins University, Baltimore, USA

In 2020, the Centers for Disease Control and Prevention (CDC) reported [1] that approximately $17 \%$ of children in the United States (US) aged 3-17 have some form of developmental disability. Specifically, about $1.8 \%$ of children in the US have a diagnosis of autism. Autism and many disorders of the brain, spinal cord, and musculoskeletal system have important health implications that require multidisciplinary care. Unfortunately, some of these patients with special considerations are unable to tolerate routine care, possibly due to factors such as inability to understand and communicate [2] care preferences, insufficient patient-specific training [3] for providers, and difficulty coordinating multidisciplinary care [4]. It is unclear how many patients with autism are diagnosed with severe, or level three, autism, categorized [5] by the Diagnostic and Statistical Manual of Mental Disorders (DSM-5) as having significant difficulties with verbal and nonverbal communication, struggling with unexpected events, and requiring substantial support. Upon review of the literature, it appears these patients are at risk for health care disparities as it relates to their access to developmentally appropriate anesthesia services, which are often required in this population to obtain routine medical care. We have observed that this gap in care only grows as patients age into adulthood, possibly due to limited training for adult providers in caring for patients in this population [6].

One example is Jane*, a 33-year-old female with severe autism (defined as above), who has received continued care from a combined internal medicine and pediatric physician at a quaternary care center. Because of her severe autism, Jane cannot tolerate basic medical procedures such as dental exams, gynecologic exams, blood draws, or radiologic imaging. One solution that has been considered is completing all her required medical services at one visit under general anesthesia. While providers at her healthcare facility have tentatively agreed to this plan, there are still barriers, such as coordinating

${ }^{*}$ Corresponding author: Felicia Hasta, Department of Anesthesiology and Critical Care Medicine, Division of Pediatric Anesthesiology, Johns Hopkins University, Baltimore, USA, Email: fhasta1@jhmi.edu

Citation: Hasta F, Koka R, Philip C (2021) A Potential Gap in Access to Anesthetic Care for Patients with Special Considerations. J Anesth Clin Care 8: 070.

Received: October 19, 2021; Accepted: October 26, 2021; Published: November 02, 2021

Copyright: @ 2021 Hasta F. This is an open-access article distributed under the terms of the Creative Commons Attribution License, which permits unrestricted use, distribution, and reproduction in any medium, provided the original author and source are credited.
Operating Room (OR) time in which all the required personnel can be present, familiarizing the involved providers with Jane's medical history and special considerations, and training the providers to provide developmentally appropriate care. Even with these challenges, Jane is comparatively lucky to receive primary care from a provider trained in both adult and pediatric medicine, who can appropriately advocate for her specific healthcare needs. More investigation is needed to better quantify this problem for other patients with special considerations, who may not receive adequate care as they transition from childhood to adulthood. In the meantime, institutions should consider conducting their own Quality Improvement (QI) studies to determine the need for transitional care planning and anesthesia services for these individuals.

In addition to the logistical challenges described above, we believe another barrier to adequate anesthesia services is that their utility in this population is often underrecognized or misunderstood. A cursory review of the literature revealed only a handful of dedicated sedation centers in the US. Among these, the majority are limited to anesthesia for dental procedures in outpatient settings and are not specific to the needs of patients with special considerations. One sedation center [7] in Florida has begun to address this gap in care by expanding their services to provide anesthesia for pediatric and adult patients with special considerations. They routinely provide IV sedation and oral anxiolytic therapy before procedures like MRI, CT, biopsy, drainage, Peripherally Inserted Central Catheter (PICC) insertion, wound dressing, and labs. Another [8] accommodates such patients seen for dental services by scheduling longer appointment times (often required to overcome communication challenges and increase patient comfort) and by attempting to obtain all radiographs and complete all required dental care in one appointment while under sedation.

The role of anesthesia services in an outpatient setting for patients with special considerations is similarly not well understood. Clinical trials [9] relating to the subject are often limited by small sample sizes. There is also some conflicting data on the use of specific medications in this group, which can be a barrier as safety and efficacy become concerns. For example, many patients with autism can become paradoxically dysphoric [10] rather than sedated when treated with common anesthetic medications such as midazolam, making it even more difficult to provide them with basic health services. Providers must also consider that these patients are often on many home medications such as stimulants, antipsychotics, and drugs for medical conditions related to their developmental disability, which may interact with routine anesthetic drugs. Because of these concerns, many providers are simply not comfortable prescribing oral anxiolytics for patients with special considerations, especially for routine procedures such as blood draws and imaging.

From discussions at our institution, this is often a barrier to care as these patients are often dependent on the availability of the few providers who are comfortable providing such services. Pediatric anesthesiologists are specially equipped to meet this perceived gap in care, as they are trained in both adult and pediatric populations, have advanced knowledge of sedation and anxiolytic services, and 
are familiar with treating patients with developmental and intellectual disability, which typically presents in childhood. Child life specialists are also vital to the process of care coordination for these patients, as they often are the most familiar with the patient's history and individual requirements. Many child life specialists at our institution have independently emphasized the need for formal education for all healthcare providers in treating patients with intellectual and developmental disabilities. They have also agreed that institutional guidelines on providing anesthetic services to this population, especially anxiolytics and/or sedatives prior to routinely uncomfortable procedures, would increase the quality of healthcare they receive.

More work needs to be done to better understand these gaps in care on a national level. At the institutional level, there are many options for healthcare improvement that should be considered. Adaptive care planning [11], in which a permanent record of a patient's specific needs is made and shared with all their providers, can inform providers of the best approach to each patient and allows some degree of consistency between different types of medical visits, which may help patients with autism cope better with care. These records may indicate the usefulness of anesthesia services for each patient, based on their history of requiring and tolerating such services. As the need for such services is elucidated, institutions should work toward creating safe and effective guidelines for anesthesia administration and for coordinating multidisciplinary care for these patients.

*Name has been changed to preserve patient confidentiality

\section{References}

1. Centers for Disease Control and Prevention (2020) Data \& Statistics on Autism Spectrum Disorder.
2. Doherty AJ, Atherton H, Boland P, Hastings R, Hives L, et al. (2020) Barriers and facilitators to primary health care for people with intellectual disabilities and/or autism: an integrative review. BJGP Open 25;4(3): bjgpopen20X101030

3. Heinrichs S. Health disparities in individuals with intellectual and developmental disabilities. Nebraska Dept. of Health and Human Services.

4. Ervin DA, Hennen B, Merrick J, Morad M (2014) Healthcare for persons with intellectual and developmental disability in the community. Front Public Health 2: 83.

5. Gilmore H (2019) Levels of Autism: Understanding the Different Types of ASD. Psych Central.

6. Cheak-Zamora NC, Yang X, Farmer JE, Clark M (2013) Disparities in transition planning for youth with autism spectrum disorder. J Ped 131: $447-454$.

7. https://www.leehealth.org/our-services/pediatric-sedation

8. https://americanpediatricsedation.com

9. Shokri H, Kasem AA (2019) Dexmedetomidine versus midazolam sedation for autistic children undergoing electroencephalogram: a prospective randomized trial. Ain-Shams J Anesthesiol.

10. Short JA, Calder A (2013) Anaesthesia for children with special needs, including autistic spectrum disorder. Continuing Education in Anaesthesia Critical Care \& Pain 13: 107-112.

11. Liddle M, Birkett K, Bonjour A, Risma K (2018) A collaborative approach to improving health care for children with developmental disabilities. Pediatrics 142: e20181136. 


\section{H}

Advances In Industrial Biotechnology | ISSN: 2639-5665

Advances In Microbiology Research | ISSN: 2689-694X

Archives Of Surgery And Surgical Education | ISSN: 2689-3126

Archives Of Urology

Archives Of Zoological Studies | ISSN: 2640-7779

Current Trends Medical And Biological Engineering

International Journal Of Case Reports And Therapeutic Studies | ISSN: 2689-310X

Journal Of Addiction \& Addictive Disorders | ISSN: 2578-7276

Journal Of Agronomy \& Agricultural Science | ISSN: 2689-8292

Journal Of AIDS Clinical Research \& STDs | ISSN: 2572-7370

Journal Of Alcoholism Drug Abuse \& Substance Dependence | ISSN: 2572-9594

Journal Of Allergy Disorders \& Therapy | ISSN: 2470-749X

Journal Of Alternative Complementary \& Integrative Medicine | ISSN: 2470-7562

Journal Of Alzheimers \& Neurodegenerative Diseases | ISSN: 2572-9608

Journal Of Anesthesia \& Clinical Care | ISSN: 2378-8879

Journal Of Angiology \& Vascular Surgery | ISSN: 2572-7397

Journal Of Animal Research \& Veterinary Science | ISSN: 2639-375

Journal Of Aquaculture \& Fisheries | ISSN: 2576-5523

Journal Of Atmospheric \& Earth Sciences | ISSN: 2689-8780

Journal Of Biotech Research \& Biochemistry

Journal Of Brain \& Neuroscience Research

Journal Of Cancer Biology \& Treatment | ISSN: 2470-7546

Journal Of Cardiology Study \& Research | ISSN: 2640-768X

Journal Of Cell Biology \& Cell Metabolism | ISSN: 2381-1943

Journal Of Clinical Dermatology \& Therapy | ISSN: 2378-8771

Journal Of Clinical Immunology \& Immunotherapy | ISSN: 2378-8844

Journal Of Clinical Studies \& Medical Case Reports | ISSN: 2378-880

Journal Of Community Medicine \& Public Health Care | ISSN: 2381-1978

Journal Of Cytology \& Tissue Biology | ISSN: 2378-9107

Journal Of Dairy Research \& Technology | ISSN: 2688-9315

Journal Of Dentistry Oral Health \& Cosmesis | ISSN: 2473-6783

Journal Of Diabetes \& Metabolic Disorders | ISSN: 2381-201X

Journal Of Emergency Medicine Trauma \& Surgical Care | ISSN: 2378-8798

Journal Of Environmental Science Current Research | ISSN: 2643-5020

Journal Of Food Science \& Nutrition | ISSN: 2470-1076

Journal Of Forensic Legal \& Investigative Sciences | ISSN: 2473-733X

Journal Of Gastroenterology \& Hepatology Research | ISSN: 2574-2566
Journal Of Genetics \& Genomic Sciences | ISSN: 2574-2485

Journal Of Gerontology \& Geriatric Medicine | ISSN: 2381-8662

Journal Of Hematology Blood Transfusion \& Disorders | ISSN: 2572-2999

Journal Of Hospice \& Palliative Medical Care

Journal Of Human Endocrinology | ISSN: 2572-9640

Journal Of Infectious \& Non Infectious Diseases | ISSN: 2381-8654

Journal Of Internal Medicine \& Primary Healthcare | ISSN: 2574-2493

Journal Of Light \& Laser Current Trends

Journal Of Medicine Study \& Research | ISSN: 2639-5657

Journal Of Modern Chemical Sciences

Journal Of Nanotechnology Nanomedicine \& Nanobiotechnology | ISSN: 2381-2044

Journal Of Neonatology \& Clinical Pediatrics | ISSN: 2378-878X

Journal Of Nephrology \& Renal Therapy | ISSN: 2473-7313

Journal Of Non Invasive Vascular Investigation | ISSN: 2572-7400

Journal Of Nuclear Medicine Radiology \& Radiation Therapy | ISSN: 2572-7419

Journal Of Obesity \& Weight Loss | ISSN: 2473-7372

Journal Of Ophthalmology \& Clinical Research | ISSN: 2378-8887

Journal Of Orthopedic Research \& Physiotherapy | ISSN: 2381-2052

Journal Of Otolaryngology Head \& Neck Surgery | ISSN: 2573-010X

Journal Of Pathology Clinical \& Medical Research

Journal Of Pharmacology Pharmaceutics \& Pharmacovigilance | ISSN: 2639-5649

Journal Of Physical Medicine Rehabilitation \& Disabilities | ISSN: 2381-8670

Journal Of Plant Science Current Research | ISSN: 2639-3743

Journal Of Practical \& Professional Nursing | ISSN: 2639-568

Journal Of Protein Research \& Bioinformatics

Journal Of Psychiatry Depression \& Anxiety | ISSN: 2573-0150

Journal Of Pulmonary Medicine \& Respiratory Research | ISSN: 2573-0177

Journal Of Reproductive Medicine Gynaecology \& Obstetrics | ISSN: 2574-2574

Journal Of Stem Cells Research Development \& Therapy | ISSN: 2381-2060

Journal Of Surgery Current Trends \& Innovations | ISSN: 2578-7284

Journal Of Toxicology Current Research | ISSN: 2639-3735

Journal Of Translational Science And Research

Journal Of Vaccines Research \& Vaccination | ISSN: 2573-0193

Journal Of Virology \& Antivirals

Sports Medicine And Injury Care Journal | ISSN: 2689-8829

Trends In Anatomy \& Physiology | ISSN: 2640-7752

Submit Your Manuscript: https://www.heraldopenaccess.us/submit-manuscript 